\title{
Uterine prolapse with bilateral hydronephrosis, suspension of vault to iliococcygeus fascia
}

\author{
Smita Anand Bijwe ${ }^{1 *}$, Umesh V. Deshmukh², Monali Deshmukh ${ }^{1}$
}

${ }^{1}$ Department of Obstetrics \& Gynaecology, PDM Medical College, Amravati, Maharashtra, India
${ }^{2}$ Department of Radiology, PDM Medical College, Amravati, Maharashtra, India

Received: 14 August 2014

Accepted: 22 August 2014

\section{*Correspondence:}

Dr. Smita Anand Bijwe,

E-mail: bijwe@rediffmail.com

(C) 2014 Bijwe SA et al. This is an open-access article distributed under the terms of the Creative Commons Attribution Non-Commercial License, which permits unrestricted non-commercial use, distribution, and reproduction in any medium, provided the original work is properly cited.

\begin{abstract}
Pelvic organ prolapse is a common health problem, and though severe morbidity is rare, it can have marked effects on quality of life. The treatment of vaginal vault prolapse can be a difficult and challenging problem. 60 year old women presented with stage IV uterine prolapse and bilateral hydronephrosis. To reinforce the support of the vagina concurrent use of iliococcygeus fascia colpopexy with the McCall culdeplasty was done for primary uterine prolapse.
\end{abstract}

Keywords: Vault prolapse, Iliococcygeus hitch, McCall culdoplasty, Bilateral hydronephrosis

\section{INTRODUCTION}

Uterine prolapse is common in India especially in rural women, possibly because of damage to the uterine supports by early child bearing, large family size, unskilled supervision of deliveries aggravated by increased intra-abdominal pressure from prolonged hours of working in the farms in the squatting position. ${ }^{1}$ Though it is uncommon, uterine prolapse can cause compression of ureters and bilateral hydronephrosis, predisposing to arterial hypertension and renal failure. ${ }^{2}$ We are presenting case of massive uterine prolapse causing bilateral hydronephrosis which is a surgical challenge.

\section{CASE REPORT}

A 60 year old post-menopausal patient was admitted in emergency with history of urinary retention and mass at vulva since 25 years .No bowel complains. Her obstetric history included four normal deliveries, the last one 27 years ago. She was hypertensive. On examination she had no neurological or musculoskeletal problems. Uterus was totally outside the vulva (procidentia); grade IV modified Baden and Walker classification. There was a severe degree of prolapse of the uterus anterior and posterior vaginal wall (Figure 1). On reduction of prolapse, no stress incontinence was demonstrable. The patient was admitted, prolapse reduced, bladder drained with indwelling catheter and atrophic vagina packed with estrogen cream to improve the quality of the vaginal mucosa. Ultrasound revealed bilateral moderate hydronephrosis (Figure 2), BUN \& Sr. creatinine were raised.

One week later, under regional anaesthesia patient underwent vaginal hysterectomy, suspension of the vaginal vault (to prevent a vault prolapse) and repair of the cystocoele, rectocoele and enterocele. Important precautions during surgery were to protect ureters and avoid bladder injury. After hysterectomy McCall culdoplasty was done by using a permanent suture (i.e., 0-silk) incorporating both uterosacral ligaments and posterior peritoneum thus obliterating the enterocele sac. This was suspended to full thickness of the apical vaginal wall. Posterior vaginal wall was opened along the entire 
length and dissected from rectovaginal septum. Permanent, monofilament sutures were placed bilaterally between the apical lateral vaginal wall and the iliococcygeus muscle anterior to the ischial spine.

10 -Prolene suture is placed at both apical sulcus and tie submucosally to avoid exposure in vagina. Tears in the rectovaginal septum as described by Richardson were identified and approximated with interrupted sutures. ${ }^{3}$ Perineorrhaphy was performed through the same incision by recreating the normal anatomic relationships of the rectovaginal septum and the muscles of the perineal body using interrupted sutures. Delayed absorbable was used for both the site-specific repair and the perineorrhaphy steps.

Patient had uneventful post-operative period. Foley's catheter was removed on day 3, normal voiding was established. Residual urine was $50 \mathrm{ml}$.

On follow up three month later there was regression of hydronephrosis and renal function was normal (Figure 3). After one year patient is asymptomatic with normally suspended vagina.

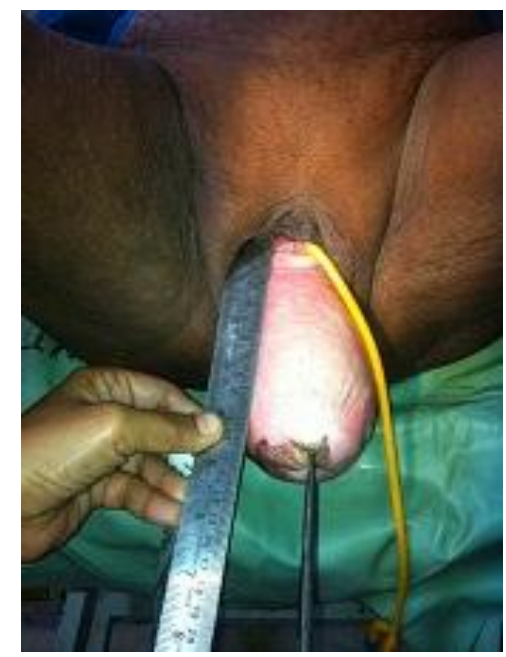

Figure 1: Grade IV uterovaginal prolapse.

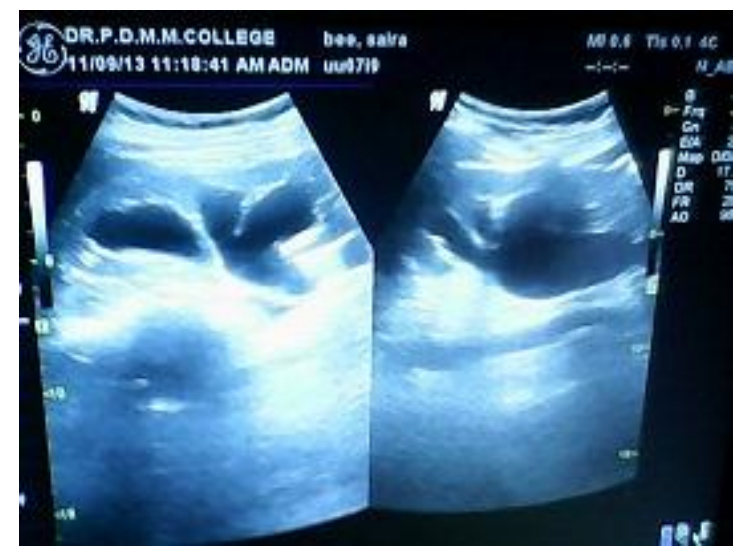

Figure 2: Bilateral moderate hydronephrosis.

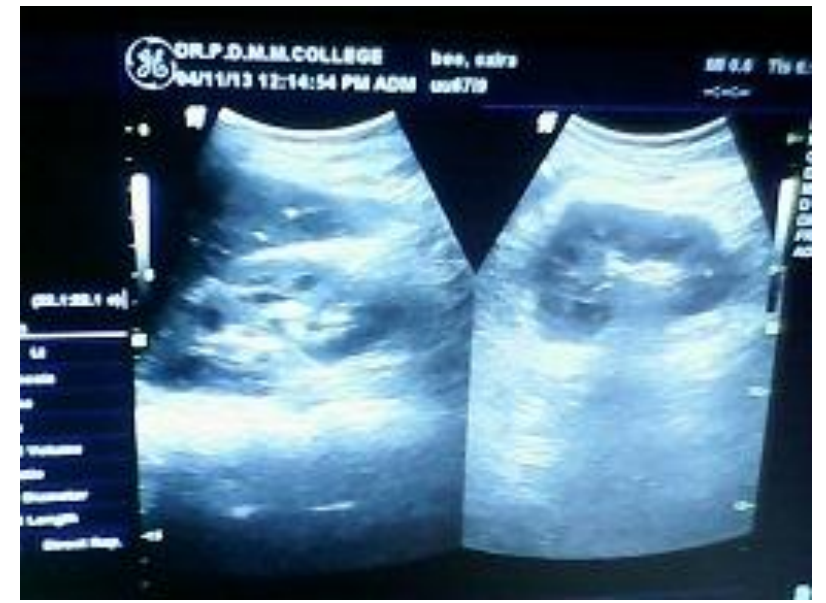

Figure 3: Regression of hydronephrosis bilaterally.

\section{DISCUSSION}

The goals of vaginal vault prolapse surgery include restoration of vaginal apical support and maintenance of normal length, axis, and caliber. To achieve a long-term successful outcome, correction of all pelvic floor defects should be achieved at the time of a vaginal vault suspension. Care must thus be taken to achieve integrity of the envelope of the anterior and posterior vaginal walls and reattaching any fascial tears off of the vaginal apex during the surgical procedure. A requirement for this procedure is sufficient vaginal length and caliber (present in this patient) such that the vaginal sidewall reaches the iliococcygeus muscle where the suture will be placed (Figure 4).

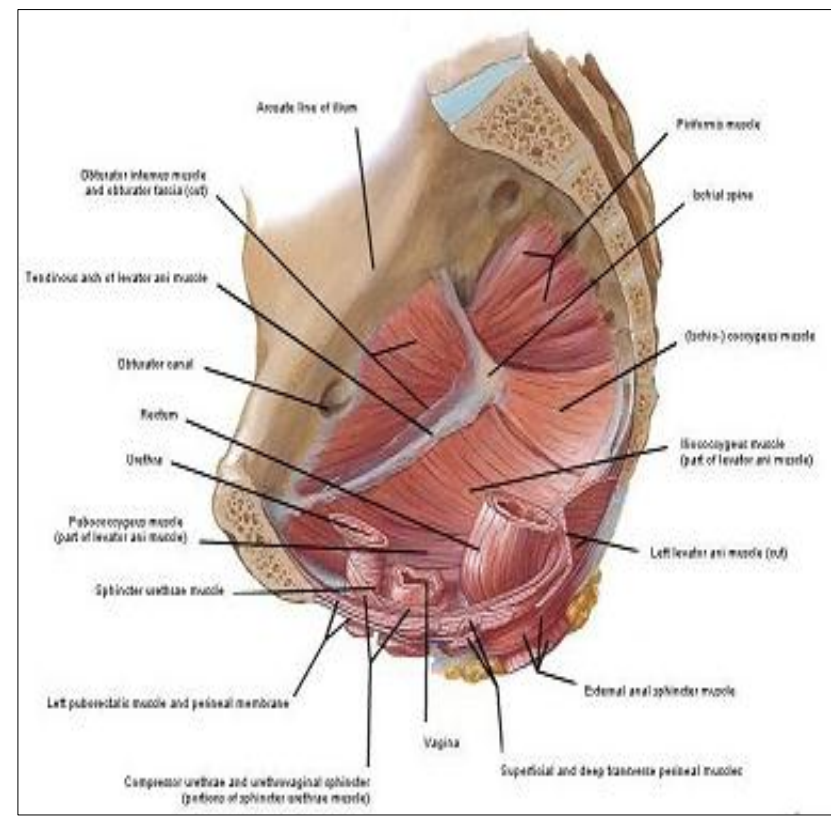

Figure 4: Pelvic diaphragm of female (medial view): location of iliococcygeus fascia and vagina.

There are few reports of use of iliococcygeus fascia for the management of patient in such situation. The 
prevalence of hydronephrosis was low in patients with POP who were candidates for surgery.

The surgical technique involves careful preoperative evaluation of the defects. Pre-operative evaluation must be complemented by another evaluation at the time of surgery. Women with prolapse of the bladder, urethra, cervix or other organs into the vagina benefit from surgery which attaches the cervix to the iliococcygeus fascia. This is simple method for restoring vaginal vault support without using graft. Advantages of vaginal route include minimal invasiveness, early mobilization, lower cost, shorter surgical time, and the simultaneous correction of co-existing cystocele and rectocele.

The iliococcygeus fascia is a fibrous tissue located laterally in the region between the end of the ischial spine and the pelvis. ${ }^{4}$

Meeks et al. identified 110 patients who had repair of vaginal vault prolapse by suspension of the vagina to iliococcygeus fascia from March 1981 to April 1991. All patients were followed for a minimum of 3 years with very low recurrence. ${ }^{5}$

The durability of the combined procedures was superior to that of the modified McCall culdeplasty alone. These results suggest that iliococcygeus fascia colpopexy (ICFC) is reasonably safe and strengthens not only the attachment of the upper part of the vagina but also that of the anterolateral vaginal wall. ${ }^{4}$

Maher demonstrated that ICFC gives durable support to the vault with very low recurrence rates. This procedure has been demonstrated in a randomized manner to be an effective means for restoring vaginal vault support. ${ }^{6}$ The creation of a central attachment site at the vaginal apex is crucial to achieving vault support and integrity of the anterior and posterior vaginal fascial envelopes.

Abdominal sacrocolpopexy is considered by many to be the gold standard procedure for repair of vaginal vault prolapse. ${ }^{7}$ Because this procedure is performed through an abdominal incision, its associated morbidity is greater than with the vaginal approaches.

Laparoscopic approaches to vault prolapse include laparoscopic sacrocolpopexy and uterosacral ligament suspension. A significant amount of laparoscopic skill is required for either procedure. ${ }^{8}$

The vaginal apex is attached to the sacrospinous ligaments with permanent or delayed absorbable sutures. The main drawback of this procedure is damage to pudendal, sciatic nerves and vascular structures. ${ }^{9}$ It can be challenging to identify the actual ligaments. In addition, there is a reported risk of ureteral trauma of $10 \%$ to $15 \%$ in published series. ${ }^{10}$

The prevalence of hydronephrosis was low in patients with POP who were candidates for surgery. POP repair usually resolves prolapse-related hydronephrosis and prevents serious long-term complications. ${ }^{2}$ Critical to the success of vaginal vault suspension are adequate dissection and repair of all fascial defects. Adequate repair of the perineal body also plays a pivotal role.

\section{CONCLUSION}

Multiple techniques are available for restoration of vaginal vault support. The procedure of choice for reconstructive surgery to the vaginal vault should be tailored to the individual patient and be of low morbidity and mortality, but at the same time with long-term durability. Suspension of the vagina to the iliococcygeus fascia for repair of vaginal vault prolapse provides excellent long-term results. Critical to the success of vaginal vault suspension are adequate dissection and repair of all fascial defects. Adequate repair of the perineal body also plays a pivotal role

Funding: No funding sources

Conflict of interest: None declared

Ethical approval: Not required

\section{REFERENCES}

1. Latha K, Kanani SJ, Maitra N. Prevalence of clinically detectable gynaecological morbidity in india: results of four community based studies. J Fam Welfare. 1997;43(4):8-16.

2. Costantini E, Lazzeri M, Mearini L, Zucchi A, Del Zingaro M, Porena M. Hydronephrosis and pelvic organ prolapsed. Urology. 2009 Feb;73(2):263-7.

3. Richardson CA. The rectovaginal septum revisited. Its relationship to rectocele and its importance to rectocele repair. Clin Obstet Gynaecol. 1993;36:97683.

4. Masayasu Koyama, Susumu Yoshida, Shinsuke Koyama. Surgical reinforcement of support for the vagina in pelvic organ prolapse: concurrent iliococcygeus fascia colpopexy (Inmon technique). Int Urogynecol J. 2005 June;16(3):197-202.

5. Meeks GR, Washburne JF, McGehee RP, Wiser WL. Repair of vaginal vault prolapse by suspension of the vagina to iliococcygeus (prespinous) fascia. Am J Obstet Gynaecol. 1994 Dec;171(6):1444-54.

6. Maher CF, Murray CJ, Carey MP, Dwyer PL, Ugoni AM. Iliococcygeus or sacrospinous fixation for vaginal vault prolapse. Obstet Gynaecol. 2001;98:404.

7. NygMcCreery R, Brubaker L, Connolly A, Cundiff G, Weber AM, Zyczynski Haard IE. Abdominal sacrocolpopexy: a comprehensive review. Obstet Gynaecol. 2004 Oct;104(4):805-23.

8. Zhu L, Sun Z, Yu M, Li B, Li X, Lang J. Modified laparoscopic sacrocolpopexy with mesh for severe pelvic organ prolapse. Int J Gynaecol Obstet. 2013 May;121(2):170-2.

9. Jones Christopher M, Hatch Kenneth D, Harrigill Keith. Unilateral and Bilateral sacrospinous ligament 
fixation for pelvic prolapse: a nonconcurrent cohort comparison. J Pelvic Surg. 2001 Jan/Feb;7(1):27-33.

10. Barber MD, Visco AG, Weidner AC, Anubdsen CL, Bump RC. Bilateral uterosacral ligament vaginal vault suspension with site-specific endopelvic fascia defect repair for treatment of pelvic organ prolapse. Am J Obstet Gynaecol. 2000;183:1402-11.

DOI: $10.5455 / 2320-1770 . i j r \operatorname{cog} 20140985$

Cite this article as: Bijwe SA, Deshmukh UV, Deshmukh M. Uterine prolapse with bilateral hydronephrosis, suspension of vault to iliococcygeus fascia. Int J Reprod Contracept Obstet Gynecol 2014;3:864-7. 